\title{
Keanekaragaman Jenis Gastropoda (Mollusca) yang Berasosiasi dengan Ekosistem Mangrove di Taman Nasional Ujung Kulon
}

\author{
Biodiversity of Gastropoda (Mollusca) Associated with Mangrove Ecosystem in Ujung \\ Kulon National Park
}

Nova Mujiono

Bidang Zoologi, Puslit Biologi-LIPI

Jl. Raya Jakarta-Bogor Km. 46 Cibinong 16911

E-mail:nova004@lipi.go.id

\begin{abstract}
A field research was conducted in Ujung Kulon National Park (TNUK) to reveal the biodiversity of Gastropoda which live associated with mangrove ecosystem. As many as 793 specimens were collected and identified. These specimen consisted of 14 families, 27 genera and 59 species which could be classified into: Native molluscs (37 species, $62.71 \%)$, Facultative molluscs $(5$ species, $\mathbf{8 . 4 7 \%}$ ) and Visitor mollusks (17 species, 28.81\%). Within Native molluscs, 19 (51.35\%) from 37 species were confirmed as new records from TNUK since they had not been recorded before. One family of Facultative molluses, the Onchidiidae (Onchidium chameleon, $O$. damelli dan $O$. patelloides) was confirmed as new record from mangrove of Java. Totally from 59 species found here, 33 species $(55.95 \%)$ were confirmed as new records, the other 26 species had already been recorded by TNUK. Some interactions (predation, mating and aggregation) among individuals were also observed in the field.
\end{abstract}

Key words: Gastropoda, Taman Nasional Ujung Kulon, mangrove, biodiversity

\begin{abstract}
Abstrak
Penelitian untuk mengungkap keanekaragaman Gastropoda yang hidup berasosiasi dengan ekosistem mangrove di Taman Nasional Ujung Kulon (TNUK) telah dilaksanakan. Sebanyak 793 spesimen telah dikoleksi dan diidentifikasi. Spesimen tersebut terdiri dari 14 suku, 27 marga dan 59 jenis yang dapat dikelompokkan menjadi : moluska asli (37 jenis, 62,71\%), moluska fakultatif $(5$ jenis, 8,47\%) dan moluska pengunjung (17 jenis, 28,81\%). Di antara moluska asli, sebanyak $19(51,35 \%)$ dari 37 jenis merupakan catatan baru dari TNUK karena belum pernah dilaporkan sebelumnya. Satu suku dari moluska fakultatif, Onchidiidae (Onchidium chameleon, $O$. damelli and $O$. patelloides) merupakan catatan baru dari mangrove di Jawa. Secara keseluruhan dari 59 jenis yang ditemukan disini, 33 jenis $(55,95 \%)$ merupakan catatan baru, lainnya sebanyak 26 jenis telah dilaporkan sebelumnya dari TNUK. Beberapa interaksi (pemangsaan, perkawinan dan pengelompokan) di antara individu juga teramati di lapangan.
\end{abstract}

Kata kunci: Gastropoda, Taman Nasional Ujung Kulon, mangrove, keanekaragaman

Diterima: 05 Juni 2009, disetujui: 28 Januari 2010

\section{Pendahuluan}

Taman Nasional Ujung Kulon (TNUK) merupakan perwakilan ekosistem hutan hujan tropis dataran rendah yang tersisa dan terluas di Jawa bagian Barat, tepatnya di ujung Barat Pulau Jawa dan masuk dalam Kabupaten Pandeglang di Provinsi Banten. Salah satu tipe ekosistem yang ada di TNUK ialah ekosistem hutan mangrove. Hutan mangrove sebagai kawasan peralihan dari ekosistem perairan laut ke darat mempunyai karakter fisika-kimia perpaduan dari keduanya (Pratiwi, 2007; Rahawarin, 2005). Hal ini menjadikannya tempat yang subur karena berperan sebagai tempat bertemunya sedimen dari laut dan darat. Kondisi lingkungan yang subur menjadi tempat ideal untuk habitat berbagai jenis hewan, salah satunya Gastropoda. 
Informasi terakhir mengenai Gastropoda mangrove dari Pulau Handeuleum di TNUK didapatkan pada tahun 1998, Yasman (1998) menemukan sebanyak 12 jenis Gastropoda pada kondisi hutan mangrove yang sebagian besar bersubstrat lumpur dan dominasi vegetasi Rhizophora sp. yang sangat rapat. Jenis-jenis Gastropoda mangrove yang ada di sekitar semenanjung Ujung Kulon kemungkinan ada kemiripan dengan di Pulau Handeuleum dan Panaitan karena lokasinya yang berdekatan. Akan tetapi meskipun begitu tetap perlu dilakukan penelitian karena selain memang belum ada penelitian di semenanjung Ujung Kulon sekaligus untuk membandingkan dengan jenis-jenis pada 10-12 tahun yang lalu pernah ditemukan di kawasan TNUK.

\section{Metode Penelitian}

Koleksi Gastropoda dilakukan 2 kali, yaitu pada musim kemarau tanggal 9-25 Juni 2008 dan pada musim hujan 3-22 Nopember 2008 pada beberapa lokasi yang meliputi muara sungai Pinanggading (PNGD), Tamanjaya (TMJY), Cilintang (CLTG), Prepet (PRPT), Cigenter (CGTR), Pulau Boboko (BBK), Cikawung (CKWG) dan Cibariang (CBRG). Pada 4 lokasi pertama dilakukan pengambilan sampel 2 kali yaitu saat musim kemarau dan hujan, sedangkan 2 lokasi berikutnya hanya sekali saat musim kemarau dan 2 lokasi terakhir hanya saat musim hujan. P. Boboko merupakan gugus pulau kecil yang terpisah dari semenanjung Ujung Kulon, sedangkan Cibariang terletak di P. Panaitan yang juga terpisah dari semenanjung Ujung Kulon. Koleksi dilakukan secara langsung dengan tangan (handling). Spesimen Gastropoda akuatik yang diperoleh dalam kondisi hidup kemudian difiksasi bertingkat menggunakan alkohol $40 \%$ dan $70 \%$. Adapun spesimen Gastropoda darat difiksasi dengan menggunakan menthol kristal yang ditambahkan ke dalam air. Keseluruhan spesimen kemudian dipreservasi dalam alkohol $70 \%$. Adapun spesimen yang ditemukan hanya berupa cangkang disimpan dalam botol plastik setelah dibersihkan dari kotoran yang melekat. Penyortiran dan identifikasi spesimen dilakukan di Museum Zoologi Bogor.

\section{Hasil dan Pembahasan}

Dalam penelitian ini telah berhasil dikoleksi sebanyak 793 individu spesimen Gastropoda dari kawasan hutan mangrove di TNUK. Mereka terbagi dalam 14 suku, 27 marga dan 59 jenis Gastropoda (Lampiran 1).

Kondisi hutan mangrove di 8 titik lokasi penelitian berbeda-beda, ada yang masih bagus dan ada juga yang sudah rusak. Hutan yang masih bagus letaknya jauh dari pemukiman penduduk, sedangkan yang sudah rusak berada dekat dengannya. Kondisi hutan mangrove diduga ikut mempengaruhi jumlah jenis Gastropoda yang ditemukan di dalamnya. Beberapa hutan mangrove yang bagus (CLTG, PRPT, CGTR, BBK, CBRG) memiliki rata-rata jumlah jenis sebanyak 16,4 jenis, sedangkan pada hutan mangrove yang rusak (PNGD, TMJY, CKWG) memiliki rata-rata jumlah jenis sebanyak 13 jenis. Hal yang menarik adalah di Tamanjaya dengan kondisi mangrove rusak ternyata memiliki jumlah jenis yang lebih bayak dibanding mangrove yang masih bagus seperti Prepet dan Cibariang (Gambar 1). Namun bila dilihat dari jumlah suku yang ada, ternyata di Tamanjaya hanya dihuni oleh 3 suku yaitu Neritidae, Potamididae dan Thiaridae sedangkan di Prepet dihuni 9 suku dan di Cibariang dihuni 6 suku.

Menurut Budiman (1991) Gastropoda mangrove di TNUK dikelompokkan menjadi 3 kelompok yaitu: 1) Moluska asli: Moluska yang sangat menggantungkan hidupnya dengan hutan mangrove dan menjadikannya sebagai tempat hidup utamanya. Contohnya: suku Potamididae, Ellobiidae, Neritidae dan Assimineidae. 2) Moluska fakultatif: Moluska yang memiliki kemampuan hidup di dalam dan di luar hutan mangrove dengan sama baiknya. Mereka ialah suku Littorinidae dan Onchidiidae. 3) Moluska pengunjung: Moluska yang keberadaannya di hutan mangrove lebih bersifat kebetulan karena tempat hidupnya berbatasan langsung dengannya. Dalam kasus ini suku Thiaridae merupakan pengunjung yang berasal dari perairan tawar dan suku Cerithidae, Muricidae, Buccinidae, Collumbelidae, Planaxidae, Trochidae dan Turbinidae berasal dari perairan laut.

Jika dilihat komposisinya berdasarkan pengelompokkan di atas, kelompok asli 
sebanyak 37 jenis $(62,71 \%)$, kelompok fakultatif 5 jenis $(8,47 \%)$ dan pengunjung 17 jenis $(28,81 \%)$. Komposisi Gastropoda asli mangrove berdasarkan jumlah jenis yaitu Neritidae 22 jenis, Ellobiidae dan Potamididae tiap-tiap 7 jenis, dan Assiminidae 1 jenis. Dari ke-37 jenis tersebut, 19 jenis $(51,35 \%)$ belum pernah dilaporkan keberadaannya pada ekosistem mangrove di TNUK, mereka adalah Neritidae: Clithon bicolor, C. corona, $C$. flavovirens, $C$. olivaceus, $C$. sowerbyana, $N$. polita, $N$. signata, N. undata, Neritina bicanaliculata, Neritina sp., Septaria lineata; Ellobiidae: Cassidula mustelina, Ellobium aurisjudae, E. aurismidae, Melampus fasciatus; Potamididae: Cerithideopsilla alata, Cerithidea quadrata, $C$. weyersi; Assiminidae: Ovassiminea brevicula.

Hasil survei musim kemarau pada 6 lokasi berhasil diidentifikasi 13 suku, 25 marga dan 43 jenis, sedangkan pada survei musim hujan pada 6 lokasi berhasil diidentifikasi sebanyak 9 suku, 19 marga dan 43 jenis. Meskipun jumlah jenis yag ditemukan pada kedua musim sama, jumlah marga dan suku lebih banyak pada musim kemarau. Fakta ini menunjukkan adanya penurunan dalam keanekaragaman jenisnya, hal ini diduga karena input volume air tawar ke hutan mangrove saat musim hujan lebih dominan sehingga menjadikan salinitas menurun tajam. Menurut sejarahnya, nenek moyang Gastropoda yang hidup di mangrove adalah berasal dari laut (Reid et al., 2008). Beberapa jenis Gastropoda yang tidak tahan terhadap salinitas rendah secara alami akan tersingkir dari wilayah hutan mangrove.
Bila dilihat jumlah keanekaragaman jenis Gastropodanya, Tamanjaya memiliki jumlah jenis terbanyak dan Cikawung dengan jumlah jenis paling sedikit. Adapun bila dilihat berdasarkan kondisi ekosistem mangrovenya, ekosistem mangrove yang sudah rusak dengan salinitas rendah mendekati air tawar (Pinanggading, Tamanjaya dan Cikawung) memiliki jumlah jenis lebih sedikit yaitu 26 jenis dibanding ekosistem mangrove dengan kondisi mangrove yang masih bagus dengan salinitas relatif tinggi (Cilintang, Prepet, Cigenter, Boboko dan Cibariang) yaitu 47 jenis. Ini menunjukkan bahwa keterkaitan antara kondisi ekosistem mangrove dan salinitas perairan terhadap keanekaragaman jenis Gastropoda adalah berbanding lurus. Hal menarik terjadi di Prepet, di mana kondisi mangrove masih bagus dan salinitas tinggi tetapi jumlah jenisnya rendah (10 jenis). Kemungkinan karena kondisi arus yang cukup deras dan waktu sampling yang kurang lama.

Kondisi ekosistem mangrove yang baik akan menyediakan bahan makanan serta tempat perlindungan dan berkembang biak bagi Gastropoda, sehingga jumlah jenis dan populasinya dapat dipertahankan. Salinitas kemungkinan bisa menjadi faktor penentu penyebaran Gastropoda mangrove, karena secara evolusi memang nenek moyang mereka berasal dari laut yang kemudian bermigrasi ke arah darat, sehingga jenis-jenis Gastropoda di mangrove lebih didominasi mereka yang tahan terhadap salinitas tinggi.

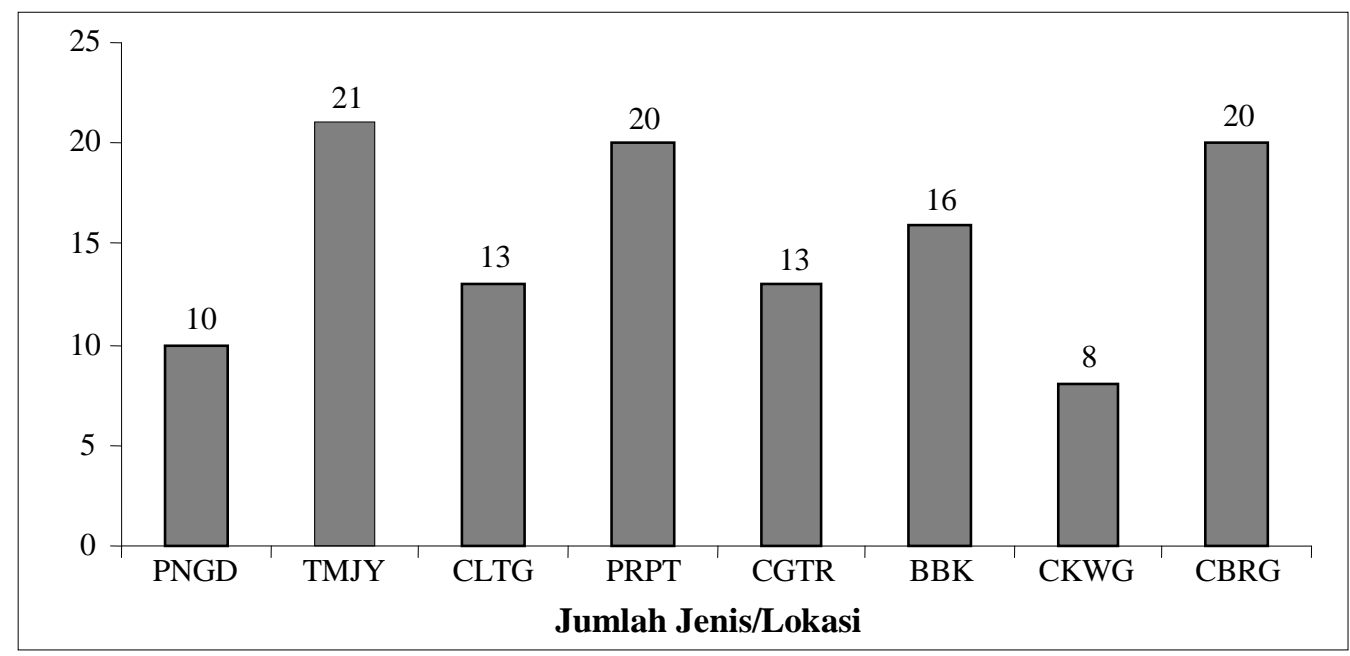

Gambar 1. Jumlah jenis Gastropoda pada tiap lokasi penelitian. 


\section{Kelompok Moluska Asli Mangrove}

Assiminea brevicula (Assiminidae) merupakan Gastropoda kecil berwarna merahoranye yang hidup di substrat lumpur berpasir pada tepian muara sungai. Mereka dijumpai di Cilintang, Prepet dan Cikawung yang banyak terdapat batang semai, kadang dengan kepadatan yang tinggi diatas permukaan lumpur. Penemuan ini merupakan catatan baru bagi Ujung Kulon karena tidak ditemukan di P. Handeuleum (Yasman, 1998) dan P. Panaitan (Moro et al., 1987 dan Butot, 1955). Assiminidae menyukai habitat yang banyak naungan (Feulner dan Hornby, 2006), pneumatophore (akar nafas) maupun batang semai untuk menempel. Karena kecil, mereka cenderung menghindari substrat yang berarus kencang. Hal ini untuk menghindari hanyut dan kemungkinan dimangsa oleh ikan dan burung. Assiminidae berperan penting sebagai pemakan detritus dan dalam daur ulang hara terutama saat suksesi awal penanaman tumbuhan mangrove (Suzuki et al., 2002).

Suku Ellobiidae merupakan kelompok Gastropoda darat dan bernafas pada udara terbuka (air-breathing) yang hidup selalu berasosiasi dengan hutan mangrove. Kebanyakan memanjat akar atau batang mangrove tetapi terlihat juga di permukaan lumpur atau menenmpel pada daun, mereka selalu mencari bagian yang teduh untuk bersembunyi (Feulner dan Hornby, 2006). Di TNUK ditemukan pada Cilintang, Cigenter, Cibariang dan Prepet. Penemuan Cassidula mustelina, Ellobium aurisjudae dan E. aurismidae merupakan catatan baru bagi Ujung Kulon karena belum pernah ditemukan di P. Handeuleum (Yasman, 1998) dan P. Panaitan (Moro et al., 1987 dan Butot, 1955). Marga Cassidula ditemukan sedang bergerak di atas substrat lumpur, sedangkan Ellobium dan Phytia lebih sering berada memanjat di tumbuhan mangrove. Phytia scarabaeus telah beradaptasi terhadap lingkungan yang kering dengan cara meletakkan telurnya pada daun yang tidak terbasahi saat pasang naik. Anggota suku Ellobiidae telah mengembangkan gerigi pada aperturenya untuk mencegah masuknya predator (Gabbi, 2000).

Suku Neritidae memiliki jumlah jenis dan sebaran yang luas, yaitu 22 jenis dan ditemukan pada semua titik lokasi. Sebanyak 11 jenis merupakan catatan baru bagi Ujung Kulon karena belum pernah ditemukan sebelumnya di P. Handeuleum (Yasman,1998) dan P. Panaitan (Moro et al., 1987 dan Butot, 1955). Marga Clithon, Neritina dan Septaria ditemukan pada perairan dengan salinitas 2-27\%o, sedangkan Nerita ditemukan pada salinitas 10-35\% . Kisaran persebaran yang luas dari perairan laut ke tawar menunjukkan pengambangan adaptasi untuk mampu bermigrasi dari laut ke darat. Neritidae merupakan pemakan alga (Blanco dan Scatena, 2007) dan juga detritus yang berada di subsrat dasar, mereka aktif di malam hari di saat pasang rendah. Suku ini sering dikonsumsi dagingnya atau cangkangnya dijadikan perhiasan (Carpenter dan Niem, 1998).

Suku Potamididae juga ditemukan pada semua titik lokasi. Penemuan Cerithideopsilla alata, Cerithidea quadrata dan $C$. weyersi merupakan catatan baru bagi Ujung Kulon karena belum pernah ditemukan sebelumnya di P. Handeuleum (Yasman, 1998) dan di P. Panaitan (Reksodihardjo et al., 1987). Cerithideopsilla ditemukan berkelompok pada lumpur dan juga batu yang berada di muara sungai. Cerithidea adalah Gastropoda pemanjat, sering ditemukan menempel menggunakan cairan mukusnya pada batang atau akar pohon mangrove terutama pada saat pasang naik. Perilaku ini bertujuan menghindari predator ikan dan kepiting. Telescopium dan Terebralia lebih sering dijumpai pada substrat lumpur, tidak memanjat akar atau batang pohon. Dimungkinkan karena ukuran cangkangnya besar dan berat sehingga menjadi hambatan saat akan memanjat (Reid et al., 2008). Karena sering terkena substrat lumpur yang asam, kebanyakan cangkang Gastropoda ini mengalami erosi pada bagian ujungnya, sehingga tampak tumpul (Nishihira et al., 2002). Potamididae umumnya adalah deposit-feeders yang memakan material partikel organik dari sedimen di substrat, terkadang mereka juga memakan diatom benthik dan alga (Bagarinao dan Olaguer, 2000). Jenis Terebralia palustris agak berbeda, di mana saat masa jevenile $(\mathrm{p}<5 \mathrm{~cm})$ adalah deposit-feeders, tetapi saat beranjak dewasa $(p>6 \mathrm{~cm})$ cenderung pemakan daun, terutama daun Rhizopora yang jatuh ke lumpur. T. palustris dewasa merupakan kompetitor bagi kepiting suku Grapsidae dan Sesarmidae yang sama-sama memakan daun 
Rhizopora (Fratini et al., 2004), sedangkan predatornya ialah kepiting dari suku Portunidae (Wells dan Lalli, 2003) dan beberapa jenis burung (Bagarinao dan Olaguer, 2000). Suku Potamididae memegang peran penting dalam proses degradasi serasah mangrove dan juga dalam perombakan nutrisi bagi ekosistem mangrove (Fratini et al., 2004). Mereka juga benyak dijadikan sumber makanan laut, meski bisa menjadi host larva cacing Trematoda pada burung. Selain itu juga potensial menjadi hama kompetitor bagi ikan Bandeng dan udang di pertambakan (Bagarinao dan Olaguer, 2000).

\section{Kelompok Moluska Fakultatif}

Littoraria scabra dan Littoraria carinifera (Littorinidae) hidup menempel pada permukaan daun ataupun batang dan akar tumbuhan mangrove yang ada di Cilintang, Prepet, Cigenter, Boboko, Cikawung dan Cibariang. Bahkan di Boboko dijumpai L. scabra menempel di daun pada ketinggian $160 \mathrm{~cm}$ dari atas substrat pasir. L. scabra sangat menyukai tumbuhan Rhizophora dan sangat jarang dijumpai pada Avicennia (Yasman, 1998). Di Cigenter $L$. carinifera dijumpai menempel pada daun Nypha. Penemuan L. carinifera merupakan catatan baru bagi Ujung Kulon karena belum pernah ditemukan di P. Handeuleum (Yasman, 1998) dan P. Panaitan (Moro et al., 1987 dan Butot, 1955). Suku ini memang menyukai daerah kanopi di mana dia telah beradaptasi secara morfologi dan fisilogi dengan baik terhadap substrat yang keras dan kering (Cantera et al., 1999). Meskipun dewasanya hidup di pohon, Gastropoda ini masih memerlukan air laut untuk proses reproduksi dan perkembangan larvanya (Heryanto et al., 1987). Gastropoda ini memakan permukaan daun tanpa merusaknya. Kadang juga memakan hifa jamur untuk membantu mengurai daun tersebut. Littorinidae memakan bermacam bagian tumbuhan mangrove mulai dari mikromakro alga sampai lichen (Christensen, 1998).

Pada survei musim hujan ditemukan 1 suku Gastropoda yaitu Onchidiide yang terdiri dari Onchidium chameleon, $O$. damelli dan $O$. patelloides yang dijumpai di Cilintang, Prepet dan Cikawung. Mereka adalah kelompok Gastropoda laut yang tak punya cangkang (sea slug). Penemuannya merupakan catatan baru karena belum pernah dijumpai pada musim kemarau dan juga mereka belum pernah dilaporkan keberadaannya pada hutan mangrove di Jawa. Pernah dijumpai di mangrove Elpa Putih, Seram-Maluku (Budiman dan Dwiono, 1987), tetapi hanya dideskripsi sampai tingkat marga Onchidium sp. Munculnya Gastropoda ini dimungkinkan karena pada musim hujan kondisi hutan mangrove lebih basah dan lembab, sehingga menarik mereka bermigrasi ke hutan mangrove. Karena tak punya cangkang, mereka lebih sensitif terhadap temperatur, selalu mencari lingkungan yang lebih lembab dan teduh menjauhi sengatan sinar matahari. Hal ini dibuktikan dengan kondisi saat mereka ditemukan yaitu menempel pada batang lapuk dan juga berada di substrat lumpur yang basah dimana keduanya terlindung oleh kanopi pohon.

\section{Kelompok Moluska Pengunjung}

Cantharus fumosus (Buccinidae) ditemukan pada bebatuan yang sedikit tergenang di Prepet. Buccinidae kebanyakan merupakan carnivora atau scavenger yang memakan Gastropoda lain atau bangkai hewan kecil (Carpenter dan Niem, 1998).

Cerythium coralium, $C$. patulum dan Clypeomorus batillariaeformis (Cerithiidae) ditemukan pada lumpur berair dan kadang menempel pada bebatuan di Prepet dan Boboko. Penemuan $C$. patulum merupakan catatan baru bagi Ujung Kulon karena tidak ditemukan di P. Handeuleum (Yasman, 1998) dan P. Panaitan (Moro et al., 1987 dan Butot, 1955). Mereka adalah herbivora pemakan alga (Carpenter dan Niem, 1998).

Pyrene ocellata (Collumbelidae) ditemukan menempel pada bebatuan di Boboko. Penemuan ini merupakan catatan baru bagi Ujung Kulon karena tidak ditemukan di P. Handeuleum (Yasman, 1998) dan P. Panaitan (Moro et al., 1987 dan Butot, 1955). Suku ini bergerak sangat aktif pada bebatuan dan karang, mereka bersifat omnivora (Budiman, 1991; Carpenter dan Niem, 1998). Corak dan warna yang menarik menjadikannya bahan hiasan dan incaran kolektor (Carpenter dan Niem, 1998). Pernah ditemukan di P. Handeuleum (Yasman, 1998).

Suku Muricidae ditemukan pada substrat lumpur berpasir, menempel pada akar mangrove dan batu di Prepet, Boboko dan Cibariang. 
Penemuan Ergalatax margariticola, Morula musiva, Thais aculeata dan $T$. carinifera merupakan catatan baru bagi Ujung Kulon karena belum pernah ditemukan di P. Handeuleum (Yasman, 1998) dan P. Panaitan (Moro et al., 1987 dan Butot, 1955). Muricidae merupakan Gastropoda predator dan aktif mencari mangsa berupa Gastropoda, kerang maupun bernakel dengan cara melobangi cangkang mangsanya. Pada beberapa jenis memproduksi sekresi yang berwarna ungu untuk melumpuhkan mangsa dan pertahanan (Carpenter dan Niem, 1998). Habitat kesukaannya ada disekitar terumbu karang (Feulner dan Hornby, 2006), kehadiran mereka di lumpur substrat berpasir kemungkinan untuk mencari mangsa. Ergalatax margariticola cenderung lebih menyukai Gastropoda suku Cerithidae dan Morula musiva lebih menyukai bernakel Tetraclita (Siang, 2003). Kehadiran suku Cerithidae di lokasi yang sama memperkuat pernyataan tersebut. Dengan memangsa bernakel yang menempel pada akar mangrove, marga Thais membantu membersihkan akar mangrove sehingga tumbuhan mangrove dapat melakukan respirasi dan absorbsi nutrisi dengan lebih baik (Kathiresan dan Bingham, 2001).

Planaxis sulcatus (Planaxidae) ditemukan menempel pada bebatuan yang tergenang air di Boboko. Penemuan merupakan catatan baru bagi Ujung Kulon karena tidak ditemukan di P. Handeuleum (Yasman, 1998) dan P. Panaitan (Moro et al., 1987 dan Butot, 1955). Jenis ini memang umum pada lingkungan berbatu dan berarus besar, dan sering ditemukan di bebatuan saat pasang rendah. Di saat cuaca panas, mereka cenderung menghindari matahari dengan memendam sebagian cangkang di lumpur (Feulner dan Hornby, 2006). Jenis ini bersifat herbivora (Mc.Killup dan Mc.Killup, 1993) dan kemungkinan menjadi salah satu mangsa dari Gastropoda Morula (Muricidae) yang juga ditemukan di Boboko, seperti yang pernah dilaporkan oleh Mc.Killup dan Mc.Killup (1993) dan Siang (2003).

Suku Thiaridae hanya dijumpai di Tamanjaya yang memang memiliki salinitas perairan rendah, cenderung ke perairan tawar (3\%o). Penemuan Melanoides maculata dan $M$ riqueti merupakan catatan baru bagi Ujung Kulon karena tidak ditemukan di P. Handeuleum
(Yasman, 1998) dan P. Panaitan (Moro et al., 1987 dan Butot, 1955). Thiaridae sejatinya merupakan Gastropoda air tawar, kehadiran mereka di ekosistem mangrove di Tamanjaya diperkirakan hanya kebetulan, karena memang muara sungai ini berbatasan langsung dengan sisa-sisa ekosistem mangrove yang masih ada di sana.

Monodonta labio (Trochidae) ditemukan menempel pada akar pohon mangrove di Boboko. Gastropoda ini merupakan pemakan alga mikro (Takada, 1995). Sering dimanfatkan penduduk pesisir pantai baik cangkangnya sebagai hiasan maupun dagingnya untuk makanan (Carpenter dan Niem, 1998).

Astraea calcar (Turbinidae) ditemukan di bebatuan berlumut di Boboko. Penemuan ini merupakan catatan baru bagi Ujung Kulon karena tidak ditemukan di P. Handeuleum (Yasman, 1998) dan P. Panaitan (Moro et al., 1987 dan Butot, 1955). Gastropoda ini bersifat herbivora, pemakan alga epibenthic dan detritus daun. Jenis ini juga sering dimanfatkan penduduk pesisir pantai baik cangkangnya sebagai hiasan maupun dagingnya untuk makanan (Carpenter dan Niem, 1998).

Beberapa interkasi antara sesama Gastropoda yang dijumpai dilokasi adalah: 1) Pemangsaan, Gastropoda predator Chicoreus capucinus dijumpai telah memangsa Terebralia palustris dan cara melubangi pada bagian punggungnya, peristiwa ini teramati di Cibariang. Populasi Chicoreus capucinus dalam jumlah besar juga teramati di Prepet, hal ini kemungkinan di sana mereka sedang mengincar mangsa Gastropoda jenis Nerita undata, Cerithidea cingualata, C. quadrata yang juga dijumpai dalam jumlah melimpah di sana. 2) Perkawinan, Sepasang individu Gastropoda Littoraria scabra saling menempelkan perutnya berhadapan dalam jangka waktu yang lama. Peristiwa ini teramati di Cibariang. 3) Berkelompok, jenis Melampus fasciatus dalam jumlah 10-15 individu bergerombol pada celah atau lubang pada kayu mati yang telah lapuk membusuk. Bahkan dalam satu batang kayu dapat dijumpai sekitar 6 kelompok. Peristiwa ini teramati di Cibariang. Kelompok Gastropoda Terebralia palustris dalam jumlah populasi sangat besar dan juga kepadatan tinggi (lebih dari 30 dalam $1 \mathrm{~m}^{2}$ ) dapat dijumpai di Cibaring 
pada bagian tengah vegetasi mangrove. Hebatnya mereka dapat hidup dengan kepadatan tersebut pada sisi kiri Sungai Cibariang di mana terdapat tumpukan sampah sangat banyak. Populasinya diperkirakan dalam keadaan puncak, di mana hanya terdapat individu dewasa dan tidak terlihat adanya juvenile.

\section{Simpulan dan Saran}

\section{Simpulan}

Berdasarkan hasil dari penelitian ini diketahui sebanyak 14 suku, 27 marga dan 59 jenis Gastropoda hidup berasosiasi dengan ekosistem hutan mangrove di Taman Nasional Ujung Kulon, yang termasuk kelompok Moluska asli sebanyak 37 jenis $(62,71 \%)$, kelompok fakultatif 5 jenis $(8,47 \%)$ dan pengunjung 17 jenis $(28,81 \%)$. Sebanyak 33 jenis $(55,95 \%)$ diketahui merupakan catatan baru bagi Taman Nasional Ujung Kulon, bahkan 3 di antaranya anggota suku Onchidiidae merupakan catatan baru bagi Pulau Jawa, sisanya 26 jenis pernah ditemukan sebelumnya dari kawasan Taman Nasional Ujung Kulon.

\section{Saran}

Masih perlu dilakukan penelitian untuk menginventarisasi keanekaragaman jenis Gastropoda mangrove di Taman Nasional Ujung Kulon, masih banyak gugus pulau kecil maupun titik vegetasi mangrove yang belum dijangkau dalam penelitian ini karena kendala transportasi. Dengan demikian akan semakin melengkapi informasi kekayaan jenis Gastropoda mangrove terutama di Pulau Jawa.

\section{Ucapan Terima Kasih}

Penelitian ini didanai dari Proyek "Evaluasi Dan Karakterisasi Biota Yang Berasosiasi Dengan Ekosistem Mangrove Di Jawa" Program Tematik DIPA LIPI tahun 2008. Untuk itu penulis mengucapkan terima kasih kepada segenap staf di Puslit Biologi LIPI atas bantuannya sehingga proyek ini dapat berjalan lancar. Tidak lupa penulis mengucapkan terima kasih kepada segenap masyarakat Desa Taman
Jaya yang telah membantu pelaksanaan kegiatan ini di lapangan.

\section{Daftar Pustaka}

Bagarinao, T. dan Olaguer, I.L. 2000. From Triphenyltins to Integrated Management of the 'Pest' Snail Cerithidea cingulata in Mangrove-derived Mikfish Ponds in the Philippines. Hydrobiologia, 437: $1-16$.

Blanco, J.B. dan Scatena, F.N. 2007. The Spatial Arrangement of Neritina virginea (Gastropoda: Neritidae) During Upstream Migration in a Split-channel Reach. River Research and Applications, 23: 235-245.

Budiman, A. dan Dwiono, S.A.P. 1987. Ekologi Gastropoda Hutan Mangrove di Jaelolo, Halmahera: Suatu Studi Perbandingan. Prosiding Seminar III Ekosistem Mangrove, Denpasar. Hal. 121-128.

Budiman, A. 1991. Penelaahan Beberapa Gatra Ekologi Gastropoda Hutan Bakau Indonesia. Disertasi Fakultas Pascsarjana Universitas Indonesia, Depok: xxii +380 hlm.

Butot, L.J.M. 1955. The Mollusc Fauna of Pulau Panaitan (Prinseneiland) Land and Freshwater Molluscs. Treubia, 23 (1): 69-135.

Cantera, J.M., Thomassin, B.A. dan Arnaud, P.M. 1999. Faunal Zoonation and Assemblages in the Pasific Colombian Mangroves. Hydrobiologia, 413: $17-33$

Carpenter, K.E. dan Niem, V.H. 1998. FAO Jenis Identification Guide for Fishery Purposes. The Living Marine Resources of The Western Central Pasific. Vol 1. Seaweeds, Corals, Bivalves and Gastropods. Pp. 1-686.

Christensen, J.T. 1998. Diet in Littoraria. Hydrobiologia 378: 235-236.

Feulner, G.R. dan Hornby, R.J. 2006. Intertidal Molluscs in UAE Lagoons. Tribulus, 16 (2): 17-23.

Fratini, S., Vigiani, V., Vannini, M. dan Cannicci, S. 2004. Terebralia palustris (Gastropoda; Potamididae) in Kenyal Mangal: Size Structure, Distribution an Impact on the Consumption of Leaf Litter. Marine Biology, 144: 1173-1182.

Gabbi, G. 2000. Shells (White Star Guides: Underwater World). Periplus, Hongkong.

Heryanto, Budiman, A. dan Sapulete, D. 1987. Beberapa Parameter Ekologi Gastropoda Hutan Mangrove di Saumlaki, Tanimbar Selatan. Prosiding Seminar III Ekosistem Mangrove, Denpasar.

Kathiresan, K. dan Bingham, B.L. 2001. Biology of Mangroves and Mangrove Ecosystems. Advances In Marine Biology, 40: 81-251. 
McKillup, S.C. dan McKillup, R.V. 1993. Behaviour of Intertidal Gastropod Planaxis sulcatus (Cerithiacea:Planaxidae) in Fiji: Are Responses to Damaged Conspecificts and Predators More Pronounced on Tropical Versus Temperate Shores? Pasific Science, 47 (4): 401-407.

Moro, D.S., Irmawati, Y., Reksodihardjo, G. dan Asmara, Y. 1987. Pola Sebaran Gastropoda di Hutan Mangrove Legon Lentah, Pulau Panaitan. Prosiding Seminar III Ekosistem Mangrove, Denpasar.

Nishihira, M., Kuniyoshi, M. dan Shimamura, K. 2002. Size Variation in Terebralia palustris (Gastropoda:Potamididae) of Iriomote Island, Southern Japan, and Its Effect on Some Population Characteristics. Wetland Ecology and Management, 10: 243-247.

Pratiwi, R. 2007. Studi Kepiting Mangrove di Delta Mahakam, Kalimantan Timur. Biota, 12 (2): 92-99.

Rahawarin, Y.Y. 2005. Komposisi Vegetasi Mangrove Di Muara Sungai Siganoi Sorong Selatan - Papua. Biota, X (3): 134-140.

Reksodihardjo, G., Irmawati, Y. dan Moro, D.S. 1987. Pola Sebaran Gastropoda Suku Potamididae di Hutan Mangrove Legon Lentah, Pulau Panaitan. Prosiding Seminar III Ekosistem Mangrove, Denpasar.

Reid, D.G., Dyal, P., Lozouet, P., Glaubrecht, M. dan Williams, S.T. 2008. Mudwhelks and Mangrove: The Evolutionary History of an Ecological Association (Gastropoda: Potamididae). Molecular Phylogenetics and Evolution, 47: 680-699.
Sabar, F., Djajasasmita, M. dan Budiman, A. 1979. Susunan dan Penyebaran Gastropoda dan Krustasea pada Beberapa Hutan Rawa Payau: Suatu Studi Pendahuluan. Prosiding Seminar Ekosistem Hutan Mangrove, Jakarta.

Siang, T.K. 2003. Feeding Ecology of Common Intertidal Muricidae (Mollusca: Neogastropoda) from the Berrup Peninsula, Western Australia. 173-190. In: Wells, F.E., Walker, D.I. \& Jones, D.S. (Eds). The Marine Flora and Fauna of Dampier, Western Australia. Western Australian Museum, Perth.

Suzuki, T., Nishihira, M. dan Paphavasit, N. 2002. Size Structure and Distribution of Ovassiminea brevicula (Gastropoda) in a Thai Mangrove Swamp. Wetlands Ecology and Management 10: 265-271.

Takada, Y. 1995.Variation of Growth Rate with Tidal Level in The Gastropod Monodonta labio on a Boulder Shore. Marine Ecology Progress Series, 117: 103-110.

Wells, F.E. dan Lalli, C.M. 2003. Aspects of the Ecoogy of the Mudwhelks Terebralia palustris and T.semistriata in Northwestern Australia. In: Wells, F.E., Walker, D.I. and Jones, D.S. (Eds). The Marine Flora and Fauna of Dampier, Western Australia. Western Australian Museum, Perth.

Yasman. 1998. Struktur Komunitas Gastropoda (Gastropoda) Hutan Mangrove di Pantai Barat Pulau Handeuleum, Taman Nasional Ujung Kulon dan Pantai Utara Pulau Penjaliran Barat, Teluk Jakarta: Studi Perbandingan. Prosiding Seminar IV Ekosistem Mangrove, Pekanbaru. 